\title{
ITÁLIA E BRASIL NA EXPO 2015
}

\section{ITALY AND BRAZIL IN THE EXPO 2015}

\author{
Aniello Angelo Avella \\ Università degli Studi di Roma Tor Vergata (UNIROMA), Roma, Itália, nelloavella@ig.com.br
}

\begin{abstract}
RESUMO
Tendo como tema "Feeding the planet, Energy for life", a Exposição Universal de Milão 2015 proporcionou ao visitante uma viagem ao redor do mundo através de culturas e inovações dos países participantes. Diferentemente das edições anteriores, que em geral representavam momentos de celebração da potência da técnica e da economia como motores de um progresso ilimitado, o evento realizado na Itália propus um paradigma novo, ao colocar como questão central a reflexão e discussão dos modelos de desenvolvimento, numa perspectiva sociológica, política e antropológica voltada para a diminuição das desigualdades que hoje caracterizam as relações entre povos e pessoas. Grandes protagonistas da manifestação, Itália e Brasil ofereceram um panorama de suas excelências no campo da alimentação, com o objetivo de contribuírem para a implementação da produção agrícola, respeitando o meio ambiente e ajudando a construir um mundo mais justo e solidário.
\end{abstract}

Palavras-chave: Contribuição da Itália e do Brasil na inovação no setor alimentar; Discussão dos modelos de desenvolvimento econômico.

\begin{abstract}
Expo Milan 2015, whose theme was "Feeding the planet, Energy for life", offered visitors a trip around the world across cultures and innovations in the participating countries. In the past, these events generally represented a moment of celebration of the power of technology and economy as engines of unlimited progress; the event made in Italy, however, offered a new paradigm, placing as a central issue the question of development models, in a sociological, political and anthropological view overcoming inequalities that today characterize relations between nations and people. Italy and Brazil, the great protagonists of the event, presented a view of their excellence in the field of feeding. Their aim was to contribute to the increase of agricultural production, respecting the natural environment and helping to build a more just and fraternal world.
\end{abstract}

Keywords: The contribution of Italy and Brazil to the innovation in the food industry; Discussion of the models of economic development.

Artigo recebido para publicação em outubro de 2015

Artigo aceito para publicação em dezembro de 2015

\section{INTRODUÇÃO}

\section{A Exposição Universal de Milão aconteceu entre 1 de maio e 31 de outubro de 2015, tendo como tema: "Feeding the planet, Energy for life"}

Realizada numa área de um milhão de metros quadrados, a manifestação contou com 146 países participantes, 53 pavilhões self built (construídos pelos próprios países), e várias áreas temáticas dedicadas às tradições culturais e culinárias do mundo inteiro e, mais em geral, aos assuntos 
econômicos, científicos e sociais ligados à produção e ao consumo de alimentos. Pela primeira vez na história das Exposições, esta edição contou com a presença oficial das organizações internacionais, da sociedade civil, das ONGs e das empresas.

Ao realizar uma viagem ao redor do mundo através de culturas e inovações dos vários países, o visitante foi estimulado a refletir sobre temas de importância vital para o futuro do planeta. A filosofia inspiradora do evento italiano, pois, distingui-se da das exposições anteriores, que geralmente representavam momentos de celebração da potência da técnica e da economia como motores de um progresso ilimitado. Neste caso o paradigma adotado foi outro, visando a questionar os modelos econômicos e os avanços da tecnologia no âmbito das dinâmicas que vão se manifestando na relação complexa entre fluxos globais e sociedades locais.

A partir da primeira exposição universal, realizada em Londres em 1851, tais eventos foram considerados "festas do progresso" e "espetáculos da modernidade", segundo os cânones da cultura positivista da época. Eram também ocasiões de exaltação "ufanista" das nações que disputavam espaços de mercado e domínio colonial naquela fase de expansão do imperialismo. O Palácio de Cristal inaugurado em Londres em 1851, e a Torre Eiffel em Paris em 1889, deviam ser exemplo tangível das grandezas nacionais; já a invenção do telefone de Graham Bell, apresentado durante a Exposição de Filadélfia de 1876, era uma afirmação planetária da ciência e da técnica norte-americanas (BASSIGNANA, 1997).

\section{No decorrer do século 20 as exposições começaram a ter cunho cada vez mais cultural e formador; objetivo das edições mais recentes tem sido o de favorecer o intercâmbio de conhecimentos entre povos com valores e estilos de vida diversos}

A primeira participação brasileira numa Exposição Universal foi em Londres em 1862. Com notável apoio do imperador D. Pedro II, o Brasil queria evidenciar suas grandes potencialidades agrícolas e industriais, e atrair imigrantes e investidores, inserindo-se no concerto das nações civilizadas (PESAVENTO, 1997). 
Ainda mais importante foi o apoio de D. Pedro II quando da Exposição de 1889 em Paris. 0 pavilhão do Brasil situava-se ao lado de outros países da América Latina, próximo à Torre Eiffel. Também neste caso, o principal intuito era o de oferecer aos visitantes a imagem de um país rico em terras férteis, porém não trabalhadas, aguardando europeus com vontade de fazer fortuna ao cultivá-las com métodos modernos (BARBURY, 1996).

No centenário da independência, o Brasil foi escolhido para ser anfitrião da Exposição Universal. Inaugurada no Rio de Janeiro em 7 de setembro de 1922, ela foi encerrada em 24 de julho de 1923, contando com a participação de Argentina, México, Japão, Estados Unidos, Suécia, Dinamarca, Noruega, Bélgica, Tchecoslováquia, Itália, Portugal, França, Inglaterra. Se de um lado a preparação do evento foi marcada pelas polêmicas em torno da demolição do morro do Castelo, aquela edição foi um inegável sucesso, com importante retorno no que concerne à imagem do Brasil no panorama internacional. Um dos principais legados foi a extraordinária iluminação da cidade (SCHROEDERGUDEHUS, B e RASMUSSEN, A., 1992; CIZERON, 2009).

A Itália, por sua vez, participou de todas as Exposições Universais da história; durante a "Great Exhibition” de Londres em 1851, estando a península ainda dividida em diversos estados, o público pude admirar o elevado nível das manufaturas industriais do Grão Ducado de Toscana, do Estado Pontifício, dos Estados Sardos, do Reino das Duas Sicílias, junto aos tradicionais produtos do setor agro- alimentar de todas as partes da bota. A criatividade do "made in Italy" iniciou desde logo a se impor, mostrando suas excelências nos setores da moda, da gráfica, da fotografia, do design, da alimentação, do artesanato, das produções industriais de elevado teor tecnológico (PELLEGRINO, 2014).

A grande novidade de Expo Milão 2015 está no salto de paradigma, que coloca como questão central a discussão dos modelos de desenvolvimento, incorporando a reflexão sobre a potência do limite 
No mundo atual, frente ao sistema econômico dominante, é preciso levar em séria consideração o tema dos limites sociais e ambientais do desenvolvimento; na dialética entre a potência, ou seja, o desejo de possuir tudo, e o limite, dever-se-ia procurar alcançar o equilíbrio dos dois termos. Parafraseando uma expressão do papa Francisco, a tensão continua entre plenitude e limite pode favorecer o caminho dos cidadãos.

Cabe lembrar a lição do filósofo, historiador da economia e antropólogo húngaro Karl Polanyi. No seu famoso livro A Grande Transformação: as origens de nossa época, ele analisa o processo através do qual a Revolução Industrial do século XVIII trouxe progresso no sentido dos instrumentos de produção, mas provocou uma desarticulação terrível na vida das pessoas comuns. A partir da categoria embeddedness /'incrustação', 'imersão', síntese da sua perspectiva teórica, Polanyi afirma que os indivíduos e suas relações encontram-se imersos em instituições culturais historicamente constituídas que os condicionam (MACHADO, 2010). As relações econômicas são parte dessas instituições sociais e de sua lógica, mas a Revolução Industrial gerou um novo sistema social - a Grande Transformação no qual a sociedade foi submetida ao mercado:

\footnotetext{
A Revolução Industrial foi apenas o começo de uma revolução tão extrema e radical quanto as que sempre inflamavam as mentes dos sectários, porém o novo credo era totalmente materialista, e acreditava que todos os problemas humanos poderiam ser resolvidos com o dado de uma quantidade ilimitada de bens materiais. (POLANYI, 1980, p.58).
}

A economia, portanto, se afirmou como fator dominante nas relações sociais; o mundo contemporâneo realizou uma profunda alteração na dinâmica entre os três termos fundamentais da economia prémoderna (reciprocidade, redistribuição e troca), tornando a troca o elemento básico de qualquer discurso econômico.

A filosofia de Expo Milão 2015 se inspirou, em parte, na idéia de Polanyi de que é necessário reconsiderar completamente o problema da subsistência material do homem para incrementar a nossa liberdade de adaptação criativa e, com isso, aumentar as nossas chances de sobrevivência. 


\section{Nos meses que antecederam o início da manifestação, mais de 500 personalidades internacionais da política, da cultura, do mundo empresarial se reuniram para elaborar um documento que deveria representar a "alma" da Expo.}

Os temas debatidos foram vários: direito universal à alimentação; luta contra as chamadas "agromáfias"; relação entre alimentação religião e cultura, pesquisa científica e inovação no setor agrícola; segurança alimentar; combate à obesidade e ao desperdiço de alimentos; futuro e desenvolvimento das cidades entre smart e slow city. A importância do papel das mulheres, transmissoras naturais de alimento, foi sublinhada pelo projeto "Women for Expo", visando a colocar as mulheres no miolo do evento enquanto depositárias de práticas, conhecimentos, tradições ligadas à alimentação, e possuem a capacidade de cuidar de si mesmas e dos outros através da nutrição.

Os trabalhos preparatórios, presididos pelo filósofo italiano Salvatore Veca, resultaram na elaboração da "Carta de Milão", o principal legado político e cultural da Expo, oferecido aos visitantes como motivo de reflexão para que todos se comprometam a agir de forma mais consciente na exploração dos recursos naturais e na preservação do planeta. Com a ambição de ser uma espécie de "protocolo de Kyoto sobre alimentação”, a Carta deverá ser apresentada pela Organização das Nações Unidas a todos os países membros, para que eles assumam os princípios do documento como empenho concreto na construção de um futuro do mundo mais justo e solidário.

A cidadela construída para hospedar o evento foi projetada segundo o modelo do castrum, o acampamento romano em forma de cruz, cujo marco urbanístico é visível em numerosas cidades italianas e européias. Dando formas modernas a um conceito milenar de cidade, a estrutura apresentava uma via principal mais longa, o Decumano, que se cruzava com uma via mais curta, o Cardo. Ao longo do Decumano encontravam-se os pavilhões dos Países participantes; já o Cardo era a "italian street", com o "Palazzo Itália", a única construção destinada a ficar depois da conclusão de Expo. Aos dois lados do Cardo, as regiões, províncias, regiões italianas ofereciam aos visitantes o melhor de suas características no campo da alimentação, vinho, arte, cultura. 
No cruzamento entre as duas perpendiculares, uma praça central representava o abraço simbólico da Itália ao mundo.

O pavilhão do Brasil, que desenvolvia o tema "Alimentando o mundo com soluções", explorou a metáfora da rede para mostrar a pluralidade étnica do País e a riqueza da sua biodiversidade. Focalizando os avanços tecnológicos alcançados no esforço de incrementar a produção sem prejudicar o meio ambiente, os autores do projeto quiseram simbolizar a união e flexibilidade da nação, com suas potencialidades e expectativas. A rede significa também que a terra não deve ser pisada, mas tratada com delicadeza.

\section{A cidade de Milão já hospedou uma exposição universal no ano de 1906}

Em plena "Belle Époque", o mundo olhava para o futuro com grande otimismo; o tema escolhido na ocasião foi o dos transportes, comemorando a abertura do túnel transalpino do "Sempione" que havia sido inaugurado em fevereiro de 1905, possibilitando a realização da primeira linha ferroviária direta entre Milão e Paris. Um dos pavilhões que mais fizeram sucesso foi o chamado "Parco Aerostatico", onde eram exibidos diversos tipos de balões inflados a ar ou gás. Uma das primeiras do gênero, a mostra aeronáutica representava perfeitamente o triunfo da modernidade (CARRERI, 1945; AUDENINO, 2008).

Já a Exposição Universal de 1942 estava prevista para acontecer em Roma, mas a eclosão da Segunda Guerra Mundial impossibilitou a sua realização.

O regime fascista, no momento de sua maior auge, havia planejado aproveitar a ocasião para mostrar ao mundo o rosto de uma nação potente, tendo na urbs o centro de um império baseado no mito antigo, mas voltado para o futuro. Durante os anos 1930, o debate entre arquitetos e urbanistas sobre o estilo arquitetônico a ser adotado foi muito intenso; Marcello Piacentini foi escolhido como coordenador técnico da obra inteira, com a cooperação dos melhores arquitetos da época. Foi construído ex novo um bairro chamado E.U.R. (Esposizione Universale Romana), de inspiração monumental e racionalista, 
considerado um projeto de desenvolvimento territorial ainda de grande atualidade nos nossos dias (TARQUINI, 2011).

A edição 2015 da Expo aconteceu no meio de uma crise global, que envolve não apenas a economia, mas o inteiro sistema de relações étnicas, políticas, estratégicas do planeta. Os fluxos migratórios, de proporções bíblicas, da África e da Ásia rumo ao Ocidente; os conflitos locais que se multiplicam em diversas áreas e ameaçam se transformar em guerras totais; os desequilíbrios cada vez maiores entre Países ricos e Países pobres e as crescentes desigualdades na distribuição das riquezas entre as camadas de uma mesma sociedade; todos estes problemas têm evidentes implicações com a questão do direito à alimentação.

Em seu recente livro sobre o capital no século XXI (2013), Thomas Piketty descreve os processos de concentração dos recursos e das riquezas, contestando as teses formuladas por Simon Kuznets, economista russo naturalizado estadunidense, prêmio Nobel em 1971. O autor da teoria, conhecida como a "Curva de Kuznets", em suas obras dos anos '50 e '60 havia afirmado que, na história das sociedades em industrialização, a desigualdade tenderia a subir por algum tempo, até atingir um ponto máximo, a partir do qual passaria a decrescer, de forma contínua e natural (KUZNETS, 1953; 1966; 1971).

Piketty recusa a idéia de um mercado livre e capaz de regular os desequilíbrios "espontaneamente"; as evidencias mostram que na economia globalizada a concentração da riqueza afeta a dinâmica política e as oportunidades econômicas. 0 crescimento dos rendimentos do capital nesta fase histórica, ele sublinha, é enormemente maior do que a taxa de rendimento do trabalho, gerando um aumento na desigualdade; a propriedade se torna fator dominante nas relações humanas e a sociedade cada vez mais patrimonialista; a riqueza assim gerada influencia de forma decisiva não apenas a economia, mas também as ações de governo e a legislação. Cabe às instituições frear esse processo e criar as oportunidades para que não haja predomínio dos proprietários, mas dos produtores inovadores (PIKETTY, 2013). 
No atual contexto internacional, Expo Milão 2015 ensejou uma ampla reflexão sobre temas que colocam em questão o próprio conceito de desenvolvimento. Hoje temos plena consciência, como escreveu Norbert Elias, de que numerosos aspectos das teorias propostas por pensadores, sociólogos, atores da política, são "duvidosos ou, pelo menos, necessitados de revisão" (ELIAS, 1990, p.223). A contribuição do evento italiano, o seu maior legado, está de um lado no impulso para a mais ampla revisão teórica dos modelos de desenvolvimento; do outro, no apelo dirigido a instituições, organismos políticos, associações de vária natureza, aos indivíduos do mundo inteiro, para que parafraseando de novo o papa Francisco - a terra seja sempre respeitada como mãe e irmã, evitando assim que a natureza responda com a destruição à violência dos homens.

\section{REFERÊNCIAS}

AIMONE L. e Olmo C. Le esposizioni universali. 1851-1900 Il progresso in scena. Torino: Allemandi, 1990.

ALLWOOD, J. The Great Exhibitions. London: Studio Vista, 1977.AUDENINO, P. Milano e l'Esposizione internazionale del 1906: la rappresentazione della modernità. Milano: FrancoAngeli, 2008.

BARBURY, H. "O Brasil vai a Paris em 1889: um lugar na exposição universal". Anais do Museu Paulista, vol. 4, nº 1, pp. 211-261, 1996.

BASSIGNANA, P. L. Le feste popolari del capitalismo. Esposizioni d'industria e coscienza nazionale in Europa, 17981911. Torino: Umberto Allemandi \& C., 1997.

CARRIERI, R. Milano 1865-1915. Milano: Edizioni della Chimera, 1945.

CIZERON, D. Les representations du Brésil lors des expositions universelles. Paris: Ed. L'Harmattan, 2009.

COLOMBO, P. Le Esposizioni Universali. I mestieri d'arte sulla scena del mondo.Venezia: Marsilio, 2012.

ELIAS, N. O processo civilizador. Rio de Janeiro: Zahar, 1990.(ed. orig. Basel: Verlag Haus zum Falken, 1939).

FINDLING, J. (org.). Historical Dictionary of World's Fairs and Expositions. New York: Greenwood Press, 1990.

HEIZER, A. "Ciência para todos: a exposição de Paris de 1889 em revista". Fenix: Revista de História e Estudos Culturais, ano VI, vol. 6, no 3 , jul/ago/set. 2009.

KUZNETS, S. e JENKS, E. Shares of Upper Income Groups in Income and Savings. New York: National Bureau of Economic Research, 1953.

KUTZNETS, S. Economic Growth and Structure: Selected Essays. New York: Norton, 1965. Modern Economic Growth: Rate, Structure, and Spread. New Haven: Yale University Press, 1966. 
.Economic Growth of Nations: Total Output and Production Structure. Cambridge: Belknap Press of Harvard University Press, 1971.

MACHADO CARDOSO, N.M. “ Karl Polanyi e a Nova Sociologia Económica: Notas sobre o conceito de (dis)embeddedness". Revista Crítica de Ciências Sociais, 90|2010, pp. 71-94)

MASSIDDA, L. Atlante delle grandi esposizioni universali. Storia e geografia del medium espositivo. Milano: Franco Angeli, 2011.

PELLEGRINO, A. "L'Italia alle esposizioni universali del XIX secolo:identità nazionale e strategie comunicative". Diacronie. Studi di Storia Contemporanea: Le esposizioni: propaganda e costruzione identitaria. 29/6/2014.

PÉREZ, L. H., e DEMEULANAEREDOUYÉRE, C. Les expositions universelles. Les identités au défi de la modernité. Rennes: Presses Universitaires de Rennes, 2014.

PESAVENTO, S. J. "Imagens da nação, do progresso e da tecnologia: a Exposição Universal da Filadélfia de 1876". Anais do Museu Paulista, vol. 2, no 1, jan./dez. 1994, pp. 151-168.

Exposições universais: espetáculos da modernidade do século XIX. São Paulo: Hucitec, 1997.

PIKETTY, T. Le capital au 21 siècle .Paris:Editions Du Seuil, 2013.

POLANYI, Karl. A Grande Transformação: as origens de nossa época. Rio de Janeiro: Editora Campus.1980. (ed.orig. New York: Farrar \& Rinehart, 1944).

RYDELL, R. W. e GWINN N. E. (orgs.). Fair Representation: World's Fairs and the Modern World. Amsterdam: VU University Press, 1994.

SCHROEDER-GUDEHUS, B. e RASMUSSEN, A. Les fastes du progrès. Le guide des Expositions Universelles 1851 1922. Paris: Flammarion, 1992.

TARQUINI, A. Storia della cultura fascista. Bologna: Il Mulino, 2011.

VISCONTI, A, “Da Londra 1851 a Milano 2015. Riflessioni sulle grandi esposizioni universali”, in Scienze e Ricerche n. 1, novembre 2014, pp. 40-44. 